\title{
Transoral Robotic Surgery for Treatment of Obstructive Sleep Apnea
}

\author{
Mario Milkov \\ Department of Dental Material Science and Propaedeutic of Prosthetic Dental Medicine, \\ Faculty of Dental medicine, Medical University - Varna
}

\begin{abstract}
.
The prevalence of obstructive sleep apnea (OSA) defined at an apnea-hypopnea index (AHI) $\geq 5$ was a mean of $22 \%$ in men and $17 \%$ in women in eleven published epidemiological studies published between 1993 and 2013. The gold standard treatment for OSA remains continuous positive airway pressure. Surgical treatment can
\end{abstract}

\section{Introduction}

The prevalence of obstructive sleep apnea (OSA) defined at an apnea-hypopnea index (AHI) $\geq 5$ was a mean of $22 \%$ in men and $17 \%$ in women in eleven published epidemiological studies published between 1993 and 2013. [3, 9, 10, 21, 22, 25, 37, 46, 51, 66] Obstructive sleep apnea (OSA) is a multifactorial and complex disease associated with repeated upper airway collapse during sleep, resulting in oxygen desaturations, frequent arousals, and sleep fragmentation. Untreated OSA has been shown to have significant adverse effects on cardiovascular, cerebrovascular, metabolic, and neurocognitive functions, and contribute to poor quality of life and an increased risk of death [14, $15,23,28,65,66]$

The gold standard treatment for OSA remains continuous positive airway pressure (CPAP). However, large proportions of patients do not tolerate or show consistent compliance with CPAP and require an alternative treatment. [26] However, PAP therapy is frequently limited by poor long-term compliance and adherence, and patients often do not want to use it $[5,58]$. Surgical treatment can then be offered as an option. then be offered as an option. Technological advancement has allowed tongue base reduction causing airway obstruction to be addressed using the da Vinci robotic system safely and with ease.

Keywords: Obstructive sleep apnea, Transoral Robotic Surgery, Treatment

In selected patients, trans-oral robotic surgery (TORS) has been shown to be a promising and effective option for the treatment of OSA allowing the resection of the base of the tongue (BOT) and supporting several surgical techniques. [4, 35] However, the most appropriate selection of patients for TORS is currently the main issue. For instance, the risk of TORS failure rate was reported to be significantly higher in patients with body mass index $(\mathrm{BMI})>30 \mathrm{~kg} / \mathrm{m}^{2}$. [18]

Some studies have also shown correlations between upper airway volumes measured by imaging techniques and polysomnographic parameters. [1, 7, $45,48,62]$ Thus, these anatomic findings might imply that surgical success could also be related to upper airway volumes.

\section{Application of surgical treatment}

Palatal surgery alone is ineffective in normalizing the apnea-hypopnea index (AHI) [2, 6]. Considering that OSA is characterized by multilevel airway collapse, multilevel surgery yields better outcomes [30].

Studies using drug-induced sleep endoscopy in 
the preoperative assessment of the upper airway showed that the base of the tongue and supraglottic regions are key sites of obstruction in a significant proportion of patients $[40,57]$. The aim of hypopharyngeal OSA surgery is to widen the retroglossal and hypopharyngeal airway space.

Since the introduction of uvulopalatopharyngoplasty (UPPP) in the US by Fujita et al. [12], surgical treatment for patients with obstructive sleep apnea/ hypopnea syndrome (OSAHS) was mainly directed at the level of the soft palate which was thought to be the main area of obstruction. However, the effectiveness of this surgical procedure was brought into question in a large meta-analysis that showed UPPP to be effective in less than $50 \%$ of the cases [47]. At the same time, surgeons began to realize that OSAHS is a disease entity that is much more complex than previously appreciated. The obstruction may involve multiple levels of the upper airway from the level of nose down to glottis.

Base of tongue (BOT) resection for treatment of OSAHS is not a new concept. Recognizing the important contribution of BOT obstruction in OSAHS , Fujita fi rst reported on the use of carbon dioxide laser for midline glossectomy in 12 patients [13]. Perhaps due to the complexity of the surgery and the potential for major complications, this procedure never became popular.

Over the years, many tongue base procedures have been reported, including volumetric tongue base reduction procedures using extensive transcervical approaches to the tongue base area, radiofrequency reduction, midline glossectomy, lingual plasty, and submucosal minimally invasive lingual excision (SMILE), as well as procedures that increase tension on the genioglossal and geniohyoid muscles (genial tubercle advancements and hyoid suspension). Unfortunately, consistency in the results was lacking and "risk to lingual artery and hypoglossal nerve prevented more aggressive tongue reduction techniques"[ 24]

The increased recognition of BOT as an important site of upper airway obstruction was in part due to the increasing use of sleep endoscopy $[40,49]$ as a diagnostic tool. As a result of this increased awareness, multiple surgical approaches directed at the BOT level have been described. These techniques included mandibulotomy with genioglossus advancement [41], hyoid advancement [43], Repose $^{\circledR}$ tongue suspension [63], radiofrequency base of tongue reduction (RFBOT) [64], submuco- sal minimally invasive lingual excision (SMILE) [34], coblation-assisted lingual tonsillectomy [31, 44], midline laser glossectomy [13], maxillomandibular advancement (MMA) [42], and implanted upper airway stimulation device [52]. Reports of surgical effectiveness of these procedures vary widely in the literature and are diffi cult to interpret due to the wide variety of diagnostic and surgical procedures employed, the complexity and uniqueness of the upper airway in individual patients, as well as the varying experience of the reporting surgeons $[6,47]$.

Transoral robotic surgery (TORS) was first described by O'Malley et al. [38] in 2006 to treat upper aerodigestive tract neoplasms. Transoral robotic surgery (TORS) for resection of oropharyngeal and supraglottic neoplasm was pioneered by Weinstein and O'Malley $[38,59,60,61]$ and gained approval by the Food and Drug Administration in December of 2009 for use in the treatment of benign and malignant conditions of oropharynx and larynx. As safety and tolerability of this procedure were established in cancer patients $[38,61]$, several investigators started to look at the use of this new technology to overcome the limitation of poor visualization and access to the BOT region for treatment of OSAHS $[11,54]$.

In 2010, Vicini et al. [53] published their preliminary report on TORS for volumetric reduction of the tongue base in their multilevel surgical management strategy for treating OSA. This pilot clinical and cadaveric anatomical study led to widespread use of this new application. Vicini et al. $[53,54]$ was the fi rst group to report its experience with TORS-assisted BOT reduction for treatment of OSAHS patients. In a group of 20 patients who underwent variety of upper airway procedures in addition to the TORS-assisted BOT reduction, the mean apnea-hypopnea index (AHI) reduced from $36.3 \pm 21.1$ to $16.4 \pm 15.2(\mathrm{p}=0.0001)$ [54].

A similar degree of mean AHI reduction [11] was later reported by Friedman et al. in a group of 27 patients who underwent robotically assisted midline glossectomy in conjunction with Z-palatoplasty (ZPP). Despite encouraging results, these reports described the use of TORS-assisted BOT resection in conjunction with other concomitant upper airway procedures making interpretation of the effi cacy and contribution of TORS- assisted BOT procedure itself diffi cult.

The da Vinci robotic system (Intuitive Surgical, 
Sunnyvale, CA, USA), with the angled scope and EndoWrist ${ }^{\circledR}$ technology, allowed the surgeon to work around the angled corner in the small oropharyngeal cavity while maintaining agility and visibility of the surgical area, thus allowing precise excision of the obstructing tongue tissue. Here, we will review the current indications and contraindications, surgical anatomy of the lingual vasculature, surgical setup and techniques, and results and complications using TORS for tongue base reduction in the multilevel surgical treatment strategy for treating OSA.

\section{Patient Selection}

Patients who have failed medical and PAP treatment for OSA with demonstrated tongue base obstruction during sleep endoscopy can be offered transoral robotic tongue base reduction. A stepwise approach (Fig. 1) starting with the patient history, clinical examination, sleep endoscopy, and counseling on options and results is required.

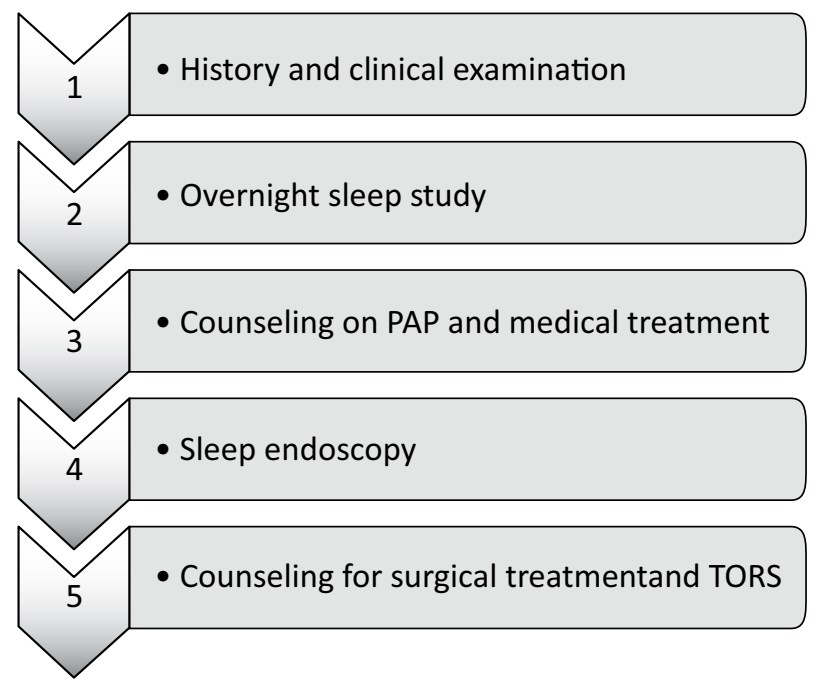

Fig. 1. The selection of patients for surgical treatment of obstructive sleep apnea and for TORS

The indications and contraindications for surgical treatment and TORS are listed in Table 1. Inadequate mouth opening and trismus is a contraindication for TORS.

Tabl. 1. Indications and contraindications for TORS

\begin{tabular}{ll}
\hline Indications & Base of tongue obstruction \\
& Lingual tonsillar enlargement \\
& Epiglottic collapse \\
& Supraglottic obstruction \\
\hline Contraindications & Severe cardiopulmonary diseases \\
& Uncontrolled psychiatric diseases \\
& Unrealistic expectations \\
& Trismus \\
& Adequate mouth opening \\
\hline
\end{tabular}

Proper patient selection is perhaps one of the most important factors to take into account when considering the applicability of a novel surgical approach. Given the limited data on a small sample size, identification of patient characteristics suitable for this TORS-assisted BOT reduction may not be possible. Despite that, the patient characteristics such as $\mathrm{BMI}<30$, $\mathrm{AHI}<60$, and absence of lateral pharyngeal collapse on DISE were associated with improved surgical outcome [33].

\section{Surgical Technique}

Robotic tongue base reduction is performed as a component of multilevel surgery treatment in conjunction with other upper airway modification surgery (nasal, palatal, and pharyngeal) in the same setting. The technique, as first described by Vicini et al. [53], is outlined below.

The patient is intubated transnasally. Silk sutures are placed on the anterior third of the tongue to pull and bring forward the base of tongue for better visualization and access by the camera endoscope. The mouth gag is introduced into the oral cavity. The Davis Meyer blade and Crow Davis gag are sufficient for adequate exposure. The robotic system is moved into position, as shown in the setup. The 2 robotic arms are moved into position and a 5 -mm cannula is fitted into the oral cavity, after which the $12 \mathrm{~mm} 30^{\circ}$ up-facing endoscope is introduced. In patients with limited mouth opening, the $8.5 \mathrm{~mm} 30^{\circ}$ up-facing endoscope may be needed. The da Vinci 5-mm EndoWrist ${ }^{\circledR}$ Maryland dissector and the monopolar diathermy are then introduced with the robotic arm.

Incision commences along the midline, starting from the foramen caecum, posterior inferior towards the vallecula. Once a trench of about $1 \mathrm{~cm}$ is created, retraction of the tissue can be achieved with Maryland forceps as the incision is further deepened. The plane of dissection and resection is created superficially to the muscles. The incision extends from the medial to lateral direction and caution is taken to avoid the laterally placed hypoglossal nerve and lingual artery. Depending on the extent of collapse and amount of tissue, a portion of muscle may be excised as well.

The right and left hemibase of the tongue will be resected on either side. The volume of excised tissue can be measured via saline displacement. A partial epiglottidectomy is performed if there is a posterior inspiratory collapse. Only the upper third 
of the epiglottis is removed to prevent aspiration. An assisting surgeon will be seated at the head of the patient with access to the patient's oral cavity and oropharynx. He or she may need to help the console surgeon retract tissue by providing counter retraction for easier dissection and resection.

\section{Subjective Outcomes Measures}

A visual analog scale was used by some authors for the patient and bed partner to evaluate subjective outcomes, including intensity and satisfaction with the results of surgery. Friedman et al. [11] reported that the snoring visual analog scale decreased from a preoperative value of $9.1 \pm 1.0$ to $2.3 \pm 3.9$ postoperatively in their patients, while Toh et al. [50] also noted that the snoring intensity of their patients reduced similarly, from $8.7 \pm 1.43$ to $3.5 \pm 1.7$

\section{Robotic Time}

The average robotic setup time reported in the literature was $24.8 \mathrm{~min}$ and average robotic operative time was $30.8 \min [33,50,56]$. With increasing experience, surgeons can expect a reduction in both the robotic setup and operative times $[50,56]$.

\section{Length of Hospital Stay}

The average length of stay was 3.2 days, ranging from $1.8 \pm 1.3$ to $9.5 \pm 2.9$ days. [8, 16, 29, 32, $39,50,54]$. Glazer et al. [16] implemented home visits by a nurse following discharge. Patients with a poor oral intake and severe pain are readmitted to a short-stay unit for hydration and analgesic treatment. Patients are instructed to seek medical attention in the event of persistent pain and dehydration.

However, Friedman et al. [11] reported that, although patients undergoing robotic surgery stayed an average of 0.5 nights longer compared to patients undergoing radiofrequency base of the tongue treatment, they did not experience more pain compared to the latter or compared to patients undergoing submucosal lingualplasty on postoperative day 1 .

\section{Complications}

Complications can result from performing TORS, and can be classified as major if they warrant surgical intervention and/or readmission, and minor if they are treated and managed conservatively.

No perioperative death associated with the use of the robotic system has been reported. Complications, according to the published literature, are tabulated in Table 2.

Tabl. 2. Complications of TORS

\begin{tabular}{ll}
\hline Major & Bleeding \\
& Dehydration \\
& Oropharyngeal adhesions and stenosis \\
& Dysphagia requiring prolonged intravenous fluids \\
\hline Minor & Bleeding \\
& Tongue numbness \\
& Dysgeusia \\
& Injury to tongue, teeth, gums, or temporal \\
& mandibular joint \\
\hline
\end{tabular}

Complications associated with TORS-assisted BOT reduction are also described elsewhere in this book. The main issues that we have encountered in our practice included taste disturbance, oropharyngeal stenosis, and bleeding.

Taste disturbance is a well-known complication following any oral procedure. In one large study involving 223 post-tonsillectomy patients, 15 (8\%) patients complain of subjective taste disturbance 6 months following tonsillectomy. On longer term follow-up, $2(0.9 \%)$ patients reported persistent dysgeusia at 21 months and 54 months following tonsillectomy [17]. Although the etiology for this complication following TORS-assisted BOT resection for OSAHS is largely unknown, possible causes include direct surgical injury to the taste buds in the BOT as well as compression and stretching injury to the branches of lingual nerve from the prolonged retraction during surgery. It is therefore important that the surgeon periodically relaxes the retractor during the case and that the patients be informed of this possible complication prior to the surgery. Fortunately, in our experience, the taste disturbance typically resolves within a few months in the majority of our patients.

Another complication that we encountered early in our experience is oropharyngeal stenosis due to scarring of BOT to tonsillar bed. These patients complained of dysphagia with solid food and typically required another surgery to release the scar tissue. Periodic Kenalog ${ }^{\circledR}$ injection in the offi ce may also help in prevention of recurrence of stenosis. In order to avoid this complication, we would recommend that a two-stage approach be considered for patients who required extensive lateral BOT resection to involve the inferior tonsillar fossa.

Due to the absence of a reliable and constant anatomic landmark, surgical intervention in the BOT 
can be burdened with the potential devastating complication of injuring the critical hypoglossal/lingual artery neurovascular bundle (HLNVB). Thus, familiarity with anatomy of the HLNVB is critically important. The average distance from the foramen cecum to the HLNVB was found to be $1.66 \pm 0.25 \mathrm{~cm}$ in a cadaver study [27] and $1.68 \pm 0.21$ $\mathrm{cm}$ in a study using computed tomographic angiography [20]. Thus, functional surgery performed within approximately $1.5 \mathrm{~cm}$ of the foramen cecum should be safe. Meticulous dissection should be carried out over the lateral tongue to avoid injury to the dorsal branch of the lingual artery.

Other complications reported in the literature that may be related to the underlying comorbid status or from the intubation process and perioperative anesthetic care include cardiac arrhythmias, hypoxemia, pulmonary embolism, reintubation, pneumonia, gum injury, and pharyngeal lacerations [19, $29,55]$.

\section{Conclusion}

Several factors seem to influence the surgical outcome in patients undergoing TORS for OSA. In particular, patients presenting with $\mathrm{BMI}<30$ $\mathrm{kg} / \mathrm{m} 2$, AHI $<60$ events/h, Friedman stage II-III, and absence of lateral pharyngeal wall collapse generally benefit more from TORS than other phenotypes. [18, 33]

However, few studies have focused their attention on the correlation between anatomic measures and surgical success. Chiffer et al. found that MRImeasured changes in the volume of the pharyngeal lateral walls correlated with changes in AHI. [8]
Technological advancement has allowed tongue base reduction causing airway obstruction to be addressed using the da Vinci robotic system safely and with ease. It is merely a tool to allow resection of the tongue base under direct vision and allows the surgeon to work around corners in the oral cavity and hypopharynx. Safe resection of an obstructing tongue base achieves improved AHI, ESS, and LSAT, with acceptable morbidity. An appropriate patient selection is paramount in yielding desirable results.

Although we demonstrate the effectiveness of TORS-assisted BOT resection as a stand-alone surgical modality in the treatment of OSAHS in some of our patients, we do not necessarily advocate the use of this surgical technique alone for treatment of OSAHS. No single surgical procedure is perfect and it is incumbent upon the surgeon to identify and select the most optimal procedure or combination of procedures to treat the anatomic obstruction unique to each OSAHS patients. A recently published meta-analysis [36] found that there is currently insufficient data to evaluate the role of glossectomy as a standalone procedure for the treatment of OSAHS. Thus, although the preliminary result on the use of TORS-assisted BOT resection for the treatment of patients with OSAHS is encouraging, its use as a stand-alone procedure cannot be advocated at this time. Further investigations are warranted and more studies need to be performed to further evaluate the efficacy, benefits, and limitations of this new technique.

\section{References}

1. Ahn SH, Kim J, Min HJ, et al. Tongue volume influences lowest oxygen saturation but not apnea-hypopnea index in obstructive sleep apnea. PLoS One. 2015;10(8):e0135796

2. Aurora RN, Casey KR, Kristo D, Auerbach S, Bista SR, Chowdhuri S, Karippot A, Lamm C, Ramar K, Zak R, Morgenthaler TI; American Academy of Sleep Medicine: Practice parameters for the surgical modifications of the upper airway for obstructive sleep apnea in adults. Sleep 2010; 33: 1408-1413

3. Bixler EO, Vgontzas AN, Ten Have T, et al. Effects of age on sleep apnea in men: I. Prevalence and severity. Am J Respir Crit Care Med $1998 ; 157: 144-8$

4. Cammaroto G, Montevecchi F, D’Agostino G, et al. Tongue reduction for OSAHS: TORSs vs coblations, technologies vs techniques, apples vs oranges. Eur Arch Otorhinolaryngol. 2016;274(2):637-645

5. Campos-Rodriguez F, Peca-Grican N, Reyes-Nucez N, De la Cruz-Moron I, Perez-Ronchel J, De la Vega-Gallardo F, Fernandez-Palacin A: Mortality in obstructive sleep apnea-hypopnea patients treated with positive airway pressure. Chest 2005; 128: 624-633

6. Caples SM, Rowley JA, Prinsell JR, Pallanch JF, Elamin MB, Katz SG, Harwick JD: Surgical modifications of the upper airway for obstructive sleep apnea in adults: a systematic review and metaanalysis. Sleep 2010; 33: 1396-1407

7. Chi L, Comyn FL, Mitra N, et al. Identification of craniofacial risk factors for obstructive sleep apnoea using three-dimensional MRI. Eur Respir J. 2011;38(2):348-358

8. Chiffer RC, Schwab RJ, Keenan BT, Borek RC, Thaler ER: Volumetric MRI analysis pre- and post-transoral robotic surgery for obstructive sleep apnea. Laryngoscope 2015; 125: 1988-1995

9. Durбn J, Esnaola S, Rubio R, et al. Obstructive sleep apnea-hypopnea and related clinical features in a population-based sample of subjects aged 30 to 70 yr. Am J Respir Crit Care Med 2001;163:685-9 
10. Franklin KA, Sahlin C, Stenlund H, et al. Sleep apnoea is a common occurrence in females. Eur Respir J 2013;41:610-5

11. Friedman M, Hamilton C, Samuelson CG, et al. Transoral robotic glossectomy for the treatment of obstructive sleep apnea-hypopnea syndrome. Otolaryngol Head Neck Surg.2012;146:854-62

12. Fujita S, Conway W, Zorick F, Roth T. Surgical correction of anatomic abnormalities in obstructive sleep apnea syndrome: uvulopalatophary ngoplasty. Otolaryngol Head Neck Surg. 1981;89:923-34

13. Fujita S, Woodson BT, Clark JL, Wittig R. Laser midline glossectomy as a treatment for obstructive sleep apnea. Laryngoscope. 1991;101:8059

14. Gami AS, Olson EJ, Shen WK, et al: Obstructive sleep apnea and the risk of sudden cardiac death: a longitudinal study of 10,701 adults. J Am Coll Cardiol 2013; 62: 10

15. Garvey JF, Pengo MF, Drakatos P, Kent BD: Epidemiological aspects of obstructive sleep apnea. J Thorac Dis 2015; 7:920-929

16. Glazer TA, Hoff PT, Spector ME: Transoral robotic surgery for obstructive sleep apnea: perioperative management and post-operative complications. JAMA Otolaryngol Head Neck Surg 2014; 140: 1207-1212

17. Heiser C, Landis BN, Giger R, et al. Taste disorders after tonsillectomy: a long-term followup. Laryngoscope. 2012;122:1265-6

18. Hoff PT, Glazer TA, Spector ME. Body mass index predicts success in patients undergoing transoral robotic surgery for obstructive sleep apnea. ORL J Otorhinolaryngol Relat Spec. 2014;76(5):266-272

19. Hoff PT, D'Agostino MA, Thaler ER: Transoral robotic surgery in benign diseases including obstructive sleep apnea:safety and feasibility. Laryngoscope $2015 ; 125: 1249-1253$

20. Hou T, Shao J, Fang S. The defi nition of the V zone for the safety space of functional surgery of the tongue. Laryngoscope. 2012;122:6670

21. Ip MS, Lam B, Lauder IJ, et al. A community study of sleep-disordered breathing in middle-aged Chinese men in Hong Kong. Chest 2001;119:62-9

22. Ip MS, Lam B, Tang LC, et al. A community study of sleep-disordered breathing in middle-aged Chinese women in Hong Kong: prevalence and gender differences. Chest 2004;125:127-34

23. Kendzerska T, Mollayeva T, Gershon AS, et al: Untreated obstructive sleep apnea and the risk for serious long-term adverse outcomes: a systematic review. Sleep Med Rev 2014; 18: 49-59

24. Kezirian EJ, Goldberg AN: Hypopharyngeal surgery in obstructive sleep apnea: an evidence-based medicine review. Arch Otolaryngol Head Neck Surg 2006; 132: 206-213

25. Kim J, In K, Kim J, et al. Prevalence of sleep-disordered breathing in middle-aged Korean men and women. Am J Respir Crit Care Med 2004;170:1108-13

26. Kribbs NB, Pack AI, Kline LR, et al. Objective measurement of patterns of nasal CPAP use by patients with obstructive sleep apnea. Am Rev Respir Dis. 1993;147(4):887-895

27. Lauretano AM, Li KK, Caradonna DS, Khosta RK, Fried MP. Anatomic location of the tongue base neurovascular bundle. Laryngoscope. 1997;107:1057-9

28. Lee W, Nagubadi S, Kryger MH, Mokhlesi B: Epidemiology of obstructive sleep apnea: a population-based perspective. Expert Rev Respir Med 2008; 2:349-364

29. Lee JM, Weinstein GS, O'Malley BW Jr, Thaler ER: Transoral robot-assisted lingual tonsillectomy and uvulopalatopharyngoplasty for obstructive sleep apnea. Ann Otol Rhinol Laryngol 2012; 121: 635-639

30. Lin HC, Friedman M, Chang HW, Gurpinar B: The efficacy of multilevel surgery of the upper airway in adults with obstructive sleep apnea/ hypopnea syndrome. Laryngoscope 2008; 118: 902- 908

31. Lin AC, Koltai PJ. Persistent pediatric obstructive sleep apnea and lingual tonsillectomy. Otolaryngol Head Neck Surg. 2009;141:81-5

32. Lin HS, Rowley JA, Badr MS, Folbe AJ, Yoo GH, Victor L, Mathog RH, Chen W: Transoral robotic surgery for treatment of obstructive sleep apnea-hypopnea syndrome. Laryngoscope 2013; 123:1811-1816

33. Lin HS, Rowley JA, Folbe AJ, Yoo GH, Badr MS, Chen W. Transoral robotic surgery for treatment of obstructive sleep apnea: factors predicting surgical response. Laryngoscope. 2015;125:1013-20

34. Maturo SC, Mair EA. Submucosal minimally invasive lingual excision: an effective, novel surgery for pediatric tongue base reduction. Ann Otol Rhinol Laryngol. 2006;115:624-30

35. Meccariello G, Cammaroto G, Montevecchi F, et al. Transoral robotic surgery (TORS) for the management of obstructive sleep apnea: a systematic review and meta-analysis. Eur Arch Otorhinolaryngol. 2016;274(2):647-653

36. Murphey AW, Kandl JA, Nguyen SA, Weber AC, Gillespie MB. The effect of glossectomy for obstructive sleep apnea: a systematic review and meta-analysis. Otolaryngol Head Neck Surg. 2015;153:334-42

37. Nakayama-Ashida Y, Takegami M, Chin K, et al. Sleep-disordered breathing in the usual lifestyle setting as detected with home monitoring in a population of working men in Japan. Sleep 2008;31:419-25

38. O’Malley BW Jr, Weinstein GS, Snyder W, Hockstein NG: Trans-oral robotic surgery (TORS) for base of tongue neoplasms. Laryngoscope 2006; 116: $1465-1472$

39. Rangabashyam M, Huang WJ, Hao Y, Han HJ, Loh S, Toh ST: State of the art transoral robotic surgery for obstructive sleep apnea. Robotic Surg Res Rev 2016; 3: 13-28

40. Ravesloot MJ, de Vries N: One hundred consecutive patients undergoing druginduced sleep endoscopy: results and evaluation. Laryngoscope $2011 ; 121: 2710-2716$

41. Riley RW, Powell NB, Guilleminault C. Maxillofacial surgery and obstructive sleep apnea: a review of 80 patients. Otolaryngol Head Neck Surg. 1989;101:353-61

42. Riley RW, Powell NB, Guilleminault C. Obstructive sleep apnea syndrome: a review of 306 consecutively treated surgical patients. Otolaryngol Head Neck Surg. 1993;108:117-25

43. Riley RW, Powell NB, Guilleminault C. Obstructive sleep apnea and the hyoid: a revised surgical procedure. Otolaryngol Head Neck Surg. $1994 ; 111: 717-21$

44. Rotenberg B, Tan S. Endoscopic-assisted radiofrequency lingual tonsillectomy. Laryngoscope. 2011;121:994-6

45. Schwab RJ, Pasirstein M, Pierson R, et al. Identification of upper airway anatomic risk factors for obstructive sleep apnea with volumetric magnetic resonance imaging. Am J Respir Crit Care Med. 2003;168(5):522-530

46. Sharma SK, Kumpawat S, Banga A, et al. Prevalence and risk factors of obstructive sleep apnea syndrome in a population of Delhi, India. Chest 2006;130:149-56 
47. Sher AE, Schechtman KB, Piccirillo JF. The effi cacy of surgical modifi cations of the upper airway in adults with obstructive sleep apnea syndrome. Sleep. 1996;19:156-77

48. Shigeta Y, Ogawa T, Ando E, Clark GT, Enciso R. Influence of tongue/mandible volume ratio on oropharyngeal airway in Japanese male patients with obstructive sleep apnea. Oral Surg Oral Med Oral Pathol Oral Radiol Endod. 2011;111(2):239-243

49. Soares D, Sinawe H, Folbe AJ, et al. Lateral oropharyngeal wall and supraglottic airway collapse associated with failure in sleep apnea surgery. Laryngoscope. 2012;122:473-9

50. Toh ST, Han HJ, Tay HN, Kiong KL: Transoral robotic surgery for obstructive sleep apnea in Asian patients: a Singapore sleep centre experience. JAMA Otolaryngol Head Neck Surg 2014; 140: 624-629

51. Udwadia ZF, Doshi AV, Lonkar SG, et al. Prevalence of sleep-disordered breathing and sleep apnea in middle-aged urban Indian men. Am J Respir Crit Care Med 2004;169:168-73

52. Van de Heyning PH, Badr MS, Baskin JZ, et al. Implanted upper airway stimulation device for obstructive sleep apnea. Laryngoscope. 2012;122:1626-33

53. Vicini C, Dallan I, Canzi P, Frassineti S, La Pietra MG, Montevecchi F: Transoral robotic tongue base resection in obstructive sleep apnoeahypopnoea syndrome: a preliminary report. ORL J Otorhinolaryngol Relat Spec 2010; 72: 22-27

54. Vicini C, Dallan I, Canzi P, et al. Transoral robotic surgery of the tongue base in obstructive sleep apnea-hypopnea syndrome: anatomic considerations and clinical experience. Head Neck. 2012;34:15-22

55. Vicini C, Montevecchi F, Magnuson JS: Robotic surgery for obstructive sleep apnea. Curr Otorhinolaryngol Rep 2013;1: 130-136

56. Vicini C, Montevecchi F, Campanini A, Dallan I, Hoff PT, Spector ME, Thaler E, Ahn J, Baptista P, Remacle M, Lawson G, Benazzo M, Canzi P: Clinical outcomes and complications associated with TORS for OSAHS: a benchmark for evaluating an emerging surgical technology in a targeted application for benign disease. ORL J Otorhinolaryngol Relat Spec 2014; 76: 63-69

57. Vroegop AV, Vanderveken OM, Boudewyns AN, Scholman J, Saldien V, Wouters K, Braem MJ, van de Heyning PH, Hamans E: Drug-induced sleep endoscopy in sleep-disordered breathing: report on 1,249 cases. Laryngoscope 2014; 124: 797-802

58. Weaver TE, Grunstein RR: Adherence to continuous positive airway pressure therapy: the challenge to effective treatment. Proc Am Thorac Soc 2008; 5: 173-178

59. Weinstein GS, O’Malley Jr BW, Snyder W, Hockstein NG. Transoral robotic surgery: supraglottic partial laryngectomy. Ann Otol Rhinol Laryngol. 2007;116:19-23

60. Weinstein GS, O’Malley Jr BW, Snyder W, Sherman E, Quon H. Transoral robotic surgery:radical tonsillectomy. Arch Otolaryngol Head Neck Surg. 2007;133:1220-6

61. Weinstein GS, O'Malley BW, Cohen MA, Quon H. Transoral robotic surgery for advanced oropharyngeal carcinoma TORS for advanced oropharyngeal carcinoma. Arch Otolaryngol Head Neck Surg. 2010;136:1079-85

62. Welch KC, Foster GD, Ritter CT, et al. A novel volumetric magnetic resonance imaging paradigm to study upper airway anatomy. Sleep. 2002;25(5):532-542

63. Woodson BT. A tongue suspension suture for obstructive sleep apnea and snorers. Otolaryngol Head Neck Surg. 2001;124:297-303

64. Woodson BT, Nelson L, Mickelson S, Huntley T, Sher A. A multi-institutional study of radiofrequency volumetric tissue reduction for OSAS. Otolaryngol Head Neck Surg. 2001;125:303-11

65. Yaggi HK, Concato J, Kernan WN, Lichtman JH, Brass LM, Mohsenin V. Obstructive sleep apnea as a risk factor for stroke and death. N Engl J Med. 2005;353(19):2034-2041

66. Young T, Palta M, Dempsey J, et al. The occurrence of sleep-disordered breathing among middle-aged adults. N Engl J Med 1993;328:12305 